\title{
ACEITAÇÃO SENSORIAL DE POLENTA DOCE CONDIMENTADO COM MARACUJÁ
}

\author{
Elder Tonete Lasaro da Costa ${ }^{1}$ \\ Maico Teodoro Silva ${ }^{2}$ \\ Weliton Barbosa de Aquino ${ }^{3}$ \\ Deusélio Bassini Fioresi ${ }^{4}$ \\ Fabiana Carvalho Rodrigues ${ }^{5}$ \\ Evandro de Andrade Siqueira ${ }^{6}$ \\ Larissa Haddad Souza Vieira ${ }^{7}$ \\ Lucas Louzada Pereira ${ }^{8}$
}

Resumo: Este trabalho teve como objetivo avaliar sensorialmente a aceitação de formulações de polenta doce condimentada com maracujá, ressaltando a necessidade de inserção de produtos inovados no mercado e, consequentemente a criação de novos nichos de mercados. A polenta é um creme à base de farinha de milho. O maracujá (Passiflora edulis) é um fruto oriundo da América do Sul. Ele é considerado uma boa fonte de vitamina $C$, levando em conta este aspecto, o fruto quando adicionado nas formulações fornece, além do sabor característico, valores nutricionais. As formulações consistem no preparo de polenta com adição de maracujá (com ou sem semente) e/ou adição de leite condensado. Como metodologia, utilizou-se do teste de aceitação, com uso de escala hedônica. Verificou-se que é possível a modificação de um produto (inovação). Os dados demostraram que a formulação que apresentou melhor média foi a com semente (resíduo) e com leite condensado.

Palavras-chave: Criação de novos produtos; Maracujá; Polenta.

\footnotetext{
${ }^{1}$ Instituto Federal de Ciência e Tecnologia do Espírito Santo, Brasil. E-mail: elder.lasaro@gmail.com.

2 Instituto Federal de Ciência e Tecnologia do Espírito Santo, Brasil. E-mail: maico.cax@gmail.com.

${ }^{3}$ Instituto Federal de Ciência e Tecnologia do Espírito Santo, Brasil. E-mail: wellbarquino@gmail.com.

${ }^{4}$ Instituto Federal de Ciência e Tecnologia do Espírito Santo, Brasil. E-mail: deuselio.fiorese@ifes.edu.br.

${ }^{5}$ Instituto Federal de Ciência e Tecnologia do Espírito Santo, Brasil. E-mail: fabiana.rodrigues@ifes.edu.br.

6 Instituto Federal de Ciência e Tecnologia do Espírito Santo, Brasil. E-mail: evandro.siqueira@ifes.edu.br.

${ }^{7}$ Instituto Federal de Ciência e Tecnologia do Espírito Santo, Brasil. E-mail: larissa.vieira@ifes.edu.br.

${ }^{8}$ Instituto Federal de Ciência e Tecnologia do Espírito Santo, Brasil. E-mail: lucas.pereira@ifes.edu.br.
} 